\title{
Outcomes following chronic obstructive pulmonary disease presentations to emergency departments in Alberta: A population-based study
}

\author{
Brian H Rowe $\mathrm{MD}^{1,2}$, Donald C Voaklander $\mathrm{PhD}^{2}$, Thomas J Marrie $\mathrm{MD}^{3}$, \\ Ambikaipakan Senthilselvan $\mathrm{PhD}^{2}$, Terry P Klassen $\mathrm{MD}^{4,5}$, Rhonda J Rosychuk PhD ${ }^{6,7}$
}

\begin{abstract}
BH Rowe, DC Voaklander, TJ Marrie, A Senthilselvan, TP Klassen, RJ Rosychuk. Outcomes following chronic obstructive pulmonary presentations to emergency departments in Alberta: A populationbased study. Can Respir J 2010;17(6):295-300.
\end{abstract}

INTRODUCTION: Chronic obstructive pulmonary disease (COPD) is a complex, multisystem disorder that often results in exacerbations requiring emergency department (ED) management. Following an exacerbation and discharge from the ED, reassessment and management adjustment with a health care provider are recommended to re-establish control of the disease. OBJECTIVES: To describe outcomes of all COPD presentations to EDs made by adults in Alberta including the time spent in the ED and the physician visits following the ED visit.

METHODS: Provincial administrative databases were used to obtain all ED encounters for COPD during six fiscal years (1999 to 2005). The information extracted included demographics, ED visit timing, and acute and subacute outcomes (physician visits up to 365 days after discharge for all 7302 discharged individuals during a one-year period). Data analysis included descriptive summaries and survival curves.

RESULTS: There were 85,330 ED visits for acute COPD, of which $67 \%$ were discharged from the ED. Median ED length of stay was longer in large urban areas (Calgary: $5 \mathrm{~h} 9 \mathrm{~min}$; Edmonton: $4 \mathrm{~h} 58 \mathrm{~min}$ ) than in other regions of Alberta (1 h $17 \mathrm{~min}$ ). Admissions resulted from $32 \%$ of visits and varied among regions; however, few were admitted to the intensive care unit $(1 \%)$ or died $(0.1 \%)$. Following discharge, the median time to first follow-up with a physician was 13 days; however, only $40 \%$ of patients had follow-up visits in the first seven days. Repeat ED visits within seven days occurred in $5.7 \%$ of discharged patients, while $25.6 \%$ of discharged patients had repeat ED visits within 365 days of discharge. CONCLUSIONS: More than $30 \%$ of COPD ED visits resulted in admission; regional variation was significant. Moreover, discharged patients experienced delayed follow-up and often required repeat ED visits. Interventions to improve reassessment and reduce COPD-related repeat ED visits should be explored.

Key Words: Chronic obstructive pulmonary disease; Databases; Emergency medicine; Epidemiology; Respiratory diseases

\author{
Les issues après des consultations attribuables à une \\ maladie pulmonaire obstructive chronique aux urgences \\ de l'Alberta : Une étude en population
}

INTRODUCTION : La maladie pulmonaire obstructive chronique (MPOC) est une maladie multisystémique complexe qui entraîne souvent des exacerbations exigeant une prise en charge à l'urgence. Après une exacerbation et un congé de l'urgence, une réévaluation et des rajustements à la prise en charge par un dispensateur de soins sont recommandés pour reprendre le contrôle de la maladie.

OBJECTIFS : Décrire les issues de toutes les consultations d'adultes de l'Alberta aux urgences en raison d'une MPOC, y compris le temps passé à l'urgence et les visites chez le médecin après la visite à l'urgence.

MÉTHODOLOGIE : Les chercheurs ont utilisé les bases de données administratives provinciales pour colliger toutes les consultations à l'urgence attribuables à un MPOC pendant six exercices financiers (1999 à 2005). L'information extraite incluait la démographie, le moment de la visite à l'urgence et les issues aiguës et sous-aiguës (visites chez le médecin jusqu'à 365 jours après le congé chez les 7302 personnes ayant obtenu leur congé sur une période d'un an). L'analyse des données contenait des sommaires descriptifs et des courbes de survie.

RÉSULTATS : Les chercheurs ont recensé 85330 visites à l'urgence attribuables à une MPOC aiguë, dont $67 \%$ ont obtenu leur congé de l'urgence. La durée médiane du séjour à l'urgence était plus longue dans les grandes régions urbaines (Calgary : $5 \mathrm{~h} 9$ min; Edmonton : $4 \mathrm{~h} 58 \mathrm{~min}$ ) que dans les autres régions de l'Alberta $(1 \mathrm{~h} 17 \mathrm{~min})$. Une hospitalisation découlait de $32 \%$ des visites et variait selon les régions. Cependant, il y avait peu d'admissions à l'unité de soins intensifs $(1 \%)$ ou de décès $(0,1 \%)$. Après le congé, la durée médiane avant le premier suivi avec un médecin était de 13 jours. Cependant, seulement $40 \%$ des patients obtenaient une visite de suivi dans les sept premiers jours. On observait une nouvelle visite à l'urgence chez 5,7 \% des patients ayant obtenu leur congé, tandis que 25,6\% des patients ayant obtenu leur congé devaient de nouveau se rendre à l'urgence dans les 365 jours suivant ce congé.

CONCLUSIONS : Plus de $30 \%$ des visites à l'urgence attribuables à la MPOC ont entraîné une hospitalisation; la variation régionale était significative. De plus, les patients ayant obtenu leur congé ont connu un retard du suivi et ont souvent dû retourner à l'urgence. Il faudrait explorer des interventions en vue d'améliorer la réévaluation et de réduire les nouvelles visites à l'urgence attribuables à la MPOC.

there are differences between countries (4) and within EDs. As a chronic disease with frequent exacerbations in many patients, presentations of COPD patients in EDs are common, and the study of their patterns is an important contributor to understanding the acute phase of this disease.

Despite the importance of this disease, surprisingly little is known about the epidemiology of the problem in the ED, especially at levels higher than an individual ED. Using large population-based, administrative health databases, we examined outcomes at the conclusion of an ED visit and subsequent follow-up visits in ED and non-ED settings for older adults presenting to EDs for COPD in Alberta during six fiscal years. severe enough to result in complications (eg, intubation or death). Treatment has been standardized through guidelines $(1,3)$; however,

${ }^{1}$ Department of Emergency Medicine; ${ }^{2}$ School of Public Health, University of Alberta, Edmonton, Alberta; ${ }^{3}$ Faculty of Medicine, Dalhousie University, Halifax, Nova Scotia; ${ }^{4}$ Department of Pediatrics and Child Health, University of Manitoba; ${ }^{5}$ Manitoba Institute of Child Health, Winnipeg,

Manitoba; ${ }^{6}$ Department of Pediatrics, University of Alberta; ${ }^{7}$ Women and Children's Health Research Institute, Edmonton, Alberta

Correspondence: Dr Rhonda J Rosychuk, Department of Pediatrics, University of Alberta, 9423 Aberhart Centre, 11402 University Avenue

Northwest, Edmonton, Alberta T6G 2J3. Telephone 780-492-0318, fax 780-407-6435, e-mail rhonda.rosychuk@ualberta.ca 


\section{METHODS}

\section{Data sources}

The present study was approved by the University of Alberta Health Research Ethics Board (Edmonton, Alberta). Data were available through the government-funded health plan in the province of Alberta. All Albertans access health care at no personal cost in a uniform, single-payer health system.

The Ambulatory Care Classification System (ACCS) (5) tracks the use of ambulatory care services to government-funded facilities within Alberta. All ED encounters in more than 100 provincial EDs are entered into computerized abstracts that constitute the majority of records. Using a uniform protocol, trained and supervised medical record nosologists code each chart using the International Classification of Diseases, 9th Revision, Clinical Modification (ICD-9-CM) (6) (before April 1, 2002) or the ICD 10th Revision, Canada (ICD-10-CA) (7) (April 1, 2002, onward) diagnostic codes.

Each ACCS record represents a unique service, and contains a unique identifier for each resident of Alberta, visit start and end dates and times, and diagnoses and disposition status. Demographic data were obtained by linking individuals in the ACCS to the annual Alberta Health Care Insurance Plan cumulative registry file. The database contains individuals registered in the Alberta Health Care Insurance Plan and does not contain individuals from the Royal Canadian Mounted Police or the Canadian military who reside in Alberta (the dependents of these individuals are included in the data if the dependent lives in Alberta). Because pharmacy information in Alberta is not collected for individuals who are younger than 65 years of age, linked pharmacy records were not available. Consequently, the influence of COPD treatments pre$\mathrm{ED}$, in the ED or following discharge could not be determined.

\section{Variable description}

Diagnostic information in the ACCS consisted of a main ambulatory diagnosis field, and five and nine additional fields for ICD-9-CM and ICD-10-CA codes, respectively. To be considered a COPD-related visit, the first or second diagnosis fields in the ACCS were required to have diagnostic codes encompassing COPD, chronic airway obstruction, bronchitis, emphysema and bronchiectasis (ICD codes 490.x, 491.x, 492.x, 494, 496, J40.x, J41.x, J42.x, J43.x, J44.x and J47.x). Studies using the ACCS indicate that the accuracy of the diagnosis is approximately $97 \%(8-10)$.

The start and end dates corresponded to the start and end of the ED service. The difference between the end date/time and the start date/time was defined as the duration of service.

All patients departing an ED are given one of nine disposition classifications according to the manner in which they are released from the ambulatory service facility. The discharged subgroup was created by defining discharged as 'discharged' or 'discharged from program or clinic'. The latter category refers to the last visit for individuals who were seen for repeat services in a treatment program. The admitted subgroup was defined as 'service recipient admitted as an inpatient to critical care unit or operating room in own facility', 'service recipient admitted as an inpatient to other area in own facility' or 'service recipient transferred to another acute care facility'. 'Service recipient expired in ambulatory care service' or 'service recipient dead on arrival to ambulatory care service' constitute deaths. The remaining classifications are 'left against medical advice (intended care not complete)' and 'left without being seen (not seen by a professional service provider)'.

Demographic information included sex, age and region of residence. All individuals were coded as male or female. Age was the age (in years) of a person at the time of the ED visit. Only individuals 55 years of age or older at the time of the ED visit were included and grouped into 55 to 59,60 to $64, \ldots, 75$ to 79 , and 80 years of age and older age categories. This age was selected because of the difficulty diagnosing COPD accurately in individuals younger than 55 years of age and the overlap with asthma (11). Until 2008, Alberta had nine regional health authorities (RHAs) responsible for the delivery of health care services. Region of residence was based on location of residence at the end of the fiscal year. The two most urban RHAs are Edmonton and Calgary (surrounding areas). The remaining seven RHAs are grouped together (nonmajor urban $[\mathrm{NMU}]$ regions) to divide the province into three regions with similar population sizes.

The Alberta government funds health care in the province, while health care insurance premiums provide partial funding. Residents with low incomes or who depend on social services (eg, welfare) are eligible for premium subsidies. The subsidy level can be used as a proxy measure of socioeconomic status. Also, many Aboriginal individuals in Alberta have 'Treaty' status based on treaties between their First Nation bands and the Canadian government (12). The subsidy level variable combines data from various fields for individuals younger than 65 years of age into four categories: 'Aboriginal with Treaty status' (A), 'Welfare' (W), 'Government-sponsored programs' (S) and 'Registrant without subsidy' (R). The W category represents individuals receiving income support and health benefits from the province of Alberta because they do not have sufficient resources to meet basic needs (eg, food and shelter). Albertans with low incomes, who receive partial or full subsidies for their health care insurance premiums or those receiving disability benefits, comprise the $\mathrm{S}$ group. For senior citizens (65 years of age and older), the subsidy variable no longer applies because seniors have been exempt from the health care insurance premiums program, and programs such as $\mathrm{W}$ are not applicable to seniors.

Follow-up visits to physicians in non-ED settings were obtained by linking the individuals in the ACCS to the individuals in the physician claims database. Alberta has very few alternative relationship or reimbursement plans, all are within the academic centres and all mandate shadow billing; no emergency departments in Alberta have alternative relationship or reimbursement plans. The data included date, three ICD-9-CM diagnosis fields, physician specialty codes and facility types. The follow-up visits within 365 days of an ED visit end date or up to October 31, 2005, were extracted and classified as COPD related if the first or second diagnosis field matched the COPD case definition. For the present study, 11 physician specialty codes (eg, respiratory medicine, thoracic surgery, general practice, cardiology, infectious diseases and internal medicine) and three facility types (eg, active treatment hospital, practitioner's office and other) were used. These categories were specified by Alberta Health and Wellness to ensure patient and practitioner anonymity.

\section{Statistical analysis}

Data from ED visits occurring between April 1, 1999, and March 31, 2005, were extracted. Frequencies and percentages, or medians and interquartile ranges (IQRs) were used to summarize the data. Kruskal-Wallis tests were used to compare means. To facilitate analyses of both subsequent ED and follow-up visits, a discharged cohort of 'index' ED visits was created, with one record per discharged individual during November 1, 2003, to October 31, 2004. For multiple presenters, one ED visit was randomly selected. This cohort captured a full year (ie, all seasons) of ED visits and 365 days of follow-up information (with October 31, 2005, as the final follow-up visit date available). The selection of one year of ED visits enabled the most recent, indepth analyses based on individuals over a relatively short time frame. The times from the index ED visit to the next ED visit, as well to the first follow-up 
TABLE 1

Chronic obstructive pulmonary disease-related emergency department visits according to disposition for each fiscal year and all years combined

\begin{tabular}{|c|c|c|c|c|c|c|c|}
\hline & \multicolumn{6}{|c|}{ Fiscal year } & \multirow[b]{2}{*}{ All years } \\
\hline & $1999 / 2000$ & $2000 / 2001$ & $2001 / 2002$ & $2002 / 2003$ & $2003 / 2004$ & $2004 / 2005$ & \\
\hline Emergency department visits, $n$ & 13,602 & 13,386 & 14,116 & 12,891 & 15,225 & 16,110 & 85,330 \\
\hline \multicolumn{8}{|l|}{ Discharged } \\
\hline Discharged & $8840(65.0)$ & $9036(67.5)$ & $9649(68.4)$ & $8633(67.0)$ & $10,271(67.5)$ & $10,791(67.0)$ & $57,220(67.1)$ \\
\hline Discharged from program or clinic & $41(0.3)$ & $24(0.2)$ & $45(0.3)$ & $24(0.2)$ & - & - & $155(0.2)$ \\
\hline \multicolumn{8}{|l|}{ Admitted } \\
\hline $\begin{array}{l}\text { Admitted to critical care unit or } \\
\text { operating room }\end{array}$ & $154(1.1)$ & $171(1.3)$ & $140(1.0)$ & $161(1.2)$ & $178(1.2)$ & $167(1.0)$ & $971(1.1)$ \\
\hline Admitted to other area & 4377 (32.2) & $3972(29.7)$ & $4045(28.7)$ & $3841(29.8)$ & $4527(29.7)$ & $4886(30.3)$ & $25,657(30.1)$ \\
\hline Admitted to another facility & $163(1.2)$ & $152(1.1)$ & $182(1.3)$ & $190(1.5)$ & $191(1.3)$ & $199(1.2)$ & $1077(1.3)$ \\
\hline \multicolumn{8}{|l|}{ Deaths } \\
\hline Expired in ambulatory care service & $9(0.1)$ & $9(0.1)$ & $14(0.1)$ & $18(0.1)$ & $9(0.1)$ & $22(0.1)$ & $81(0.1)$ \\
\hline $\begin{array}{l}\text { Expired on arrival to ambulatory care } \\
\text { service }\end{array}$ & - & - & - & - & - & - & $25(0.0)$ \\
\hline \multicolumn{8}{|l|}{ Left before completion of care } \\
\hline $\begin{array}{l}\text { Left against medical advice or left } \\
\text { without being seen }\end{array}$ & $16(0.1)$ & $17(0.1)$ & $27(0.2)$ & $18(0.1)$ & $28(0.2)$ & $38(0.2)$ & $144(0.2)$ \\
\hline
\end{tabular}

Data presented as $n$ (\%) unless otherwise indicated. - denotes low counts

visit were calculated and displayed with Kaplan-Meier curves. Time was censored at the end of the study period or the date of the next ED visit for the follow-up visit analyses. Estimated median times (and 95\% CIs) were obtained from the Kaplan-Meier curve estimates, while log-rank tests compared groups. Summaries according to subsidy level were restricted to adults younger than 65 years of age. Splus version 8.0.4 (TIBCO Software, USA) was used for data analysis and $\mathrm{P}<0.05$ was considered to be statistically significant.

\section{General trends}

\section{RESULTS}

During the six-year study period, 85,330 ED visits for COPD were made by 38,638 distinct adults. The average number of visits per individual was 2.2 (median 1, IQR 1 to 2, maximum 106); however, the majority $(24,633[63.8 \%])$ visited the ED only once, with approximately $2.3 \%(n=889)$ visiting the ED more than 10 times. More than $75 \%$ of the COPD ED visits had COPD reported in the first diagnosis field.

\section{Outcomes}

A large majority of ED visits (57,375 [67.2\%]) for COPD resulted in discharges (Table 1). For the 27,705 admissions with a primary ED diagnosis of COPD, the subsequent first diagnoses at discharge varied; however, most were related to COPD (20,848 [75.2\%]) or pulmonary infections (2916 [10.5\%]). Other common comorbid cardiac conditions (eg, heart failure, ischemic heart disease or chest pain) represented $8.3 \%$ of admissions $(n=2311)$. Other serious conditions complicating COPD (eg, pneumothorax, pulmonary embolism or stroke) were reported very infrequently (129 visits) and respiratory failure occurred in 660 admissions (2.4\%). One hundred forty-four visits were coded as 'left against medical advice' or 'left without being seen'. Deaths represented slightly more than $0.1 \%$ of visits: 25 and 81 deaths happened 'on arrival to' and 'in' ambulatory care service, respectively.

Length of stay in the ED

Of 85,330 visits, 7441 had missing start times and/or missing end dates or times, 137 had identical start and end times, and six reportedly exceeded seven days. The median length of stay (LOS) in the
ED was $2 \mathrm{~h} 23 \mathrm{~min}$ (IQR $1 \mathrm{~h}$ to $6 \mathrm{~h} 5 \mathrm{~min}$ [77,746 ED visits]). Discharged and admitted individuals had a median LOS of $1 \mathrm{~h}$ $40 \mathrm{~min}$ (IQR $48 \mathrm{~min}$ to $4 \mathrm{~h} 10 \mathrm{~min}$ [53,111 visits]) and $5 \mathrm{~h} 14 \mathrm{~min}$ (IQR 2 h 1 min to 10 h 33 min [24,430 visits]), respectively. The ED LOS was longer in the Calgary and Edmonton regions than in NMUs for visits resulting in admissions $(\mathrm{P}<0.001)$ or discharges $(\mathrm{P}<0.001)$.

\section{Discharged cohort}

Between November 1, 2003, and October 31, 2004, 10,693 ED visits resulted in discharge for 7302 individuals. These 7302 individuals formed the discharged cohort, with one visit retained per individual (ie, index visit). The discharged set was comprised of an approximately equal number of men and women; individuals 80 years of age and older formed the largest age group, and the majority of individuals were from the $\mathrm{R}$ group and the NMU regions (Table 2).

One-quarter of the patients $(25.6 \%)$ had a repeat ED visit within 365 days of discharge. Approximately 5.7\% (416 of 7302) of the patients made a repeat ED visit within seven days; $1.5 \%$ (three of 195 ) and $6.6 \%$ (21 of 320 ) of the individuals from the A and W groups, respectively, had returned to the ED within seven days (Figure 1). Other differences in time to repeat ED visit were also found: men returned earlier than women $(\mathrm{P}<0.001)$, and older age groups returned earlier than younger age groups $(\mathrm{P}<0.001)$.

Nearly $40 \%$ (2887 of 7302) of the individuals had at least one follow-up visit within seven days for any reason, and 25.8\% (744 of 2887) of these individuals had follow-up visits that were coded as COPD related. At 14 and 30 days, 54.3\% (3962 of 7302) and 68.4\% (4992 of 7302) of individuals, respectively, had a follow-up visit recorded; $26.6 \%$ (1054 of 3962) and 28.9\% (1441 of 4992) of individuals had COPD-related follow-up visits, respectively. In the seven days following the index ED visits (Table 3), there were 5749 follow-up visits and $1187(20.6 \%)$ of these were COPD related. The W subgroup comprised $13.7 \%$ of the cohort, but represented $20.7 \%$ (294 of 1419) and 20.1\% (1009 of 5014) of the follow-up visits at seven and 30 days, respectively. General practitioners and active treatment hospitals were the most common physician group and setting at seven days, respectively.

Approximately $62.2 \%$ of individuals had yet to have a non-ED follow-up visit seven days after the index ED visit. The estimated 


\begin{tabular}{ll}
$\begin{array}{l}\text { TABLE } 2 \\
\text { Demographics discharged individuals from the 2003/2004 } \\
\text { cohort (n=7302) }\end{array}$ \\
\hline Factor & $\mathbf{n}(\%)$ \\
\hline Sex & $3619(49.6)$ \\
Female & $3683(50.4)$ \\
Male & \\
Age group, years & $1270(17.4)$ \\
$55-59$ & $1060(14.5)$ \\
$60-64$ & $1142(15.6)$ \\
$65-69$ & $1176(16.1)$ \\
$70-74$ & $1133(15.5)$ \\
$75-79$ & $1521(20.8)$ \\
$\geq 80$ & \\
Subsidy group (55-64 years of age) & $195(8.4)$ \\
Aboriginal & $474(20.3)$ \\
Government-sponsored program & $320(13.7)$ \\
Welfare & $1341(57.6)$ \\
Registrant without subsidy & \\
Region(s) of residence (Alberta) & $1077(14.7)$ \\
Calgary & $1840(25.2)$ \\
Edmonton & $4385(60.1)$ \\
Nonmajor urban &
\end{tabular}

median time to the first follow-up visit was 13 days (95\% CI 12 to 13 days). Time to follow-up was shorter for older individuals $(\mathrm{P}<0.001)$ and for individuals in the two major urban areas $(\mathrm{P}<0.001$; Table 4). The time to first follow-up visit also differed according to subsidy group ( $\mathrm{P}<0.001$; Figure 2 ). The $\mathrm{A}$ and $\mathrm{S}$ groups had similar patterns, with estimated median times of 16 and 15 days, respectively. The $\mathrm{W}$ group had the shortest estimated median time (10 days) whereas the $\mathrm{R}$ group had the longest (22 days). Seven days after the ED visit, approximately $42.8 \%$ of individuals in the W group and $27.9 \%$ to $34.7 \%$ in the remaining groups had had a follow-up. Longer estimated median times were observed for the NMU regions (16 days) than the other two more urban regions (10 days).

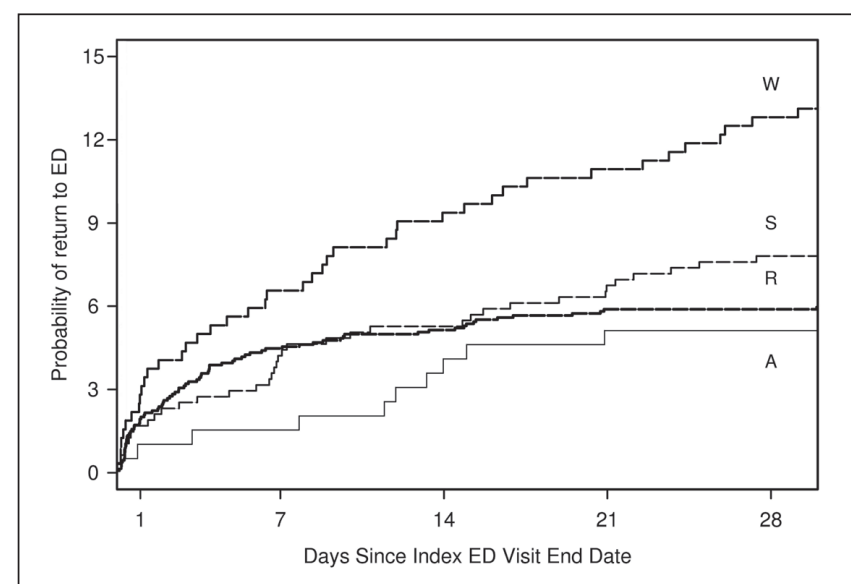

Figure 1) Time to next emergency department (ED) visit for chronic obstructive pulmonary disease after discharge from the ED. Discharged cohort with age younger than 65 years according to subsidy group. A Aboriginal; R Registrant without subsidy; S Government-sponsored programs; W Welfare

\section{DISCUSSION}

The present study linked information from more than 100 EDs in the province of Alberta with demographic variables and follow-up visits occurring in ED and non-ED settings from other comprehensive Alberta administrative databases. With this linkage, we obtained 85,330 ED visits for COPD during a six-year study period to examine ED LOS and outcomes. Within a cohort of 7302 individuals discharged during a one-year period, we described subsequent ED visits and follow-up visits in non-ED settings. The most important study findings included the following: $32 \%$ of ED visits resulted in admission, ED LOS differed according to region, and follow-up after an ED visit was delayed and highly variable.

The outcomes for ED patients presenting with this disease differ from that seen in other respiratory conditions such as asthma (13). In our previous work (13), only $9 \%$ of patients with asthma

TABLE 3

Nonemergency department (non-ED) follow-up visits for the discharged cohort $(n=7302)$

\begin{tabular}{|c|c|c|c|c|c|}
\hline & \multicolumn{5}{|c|}{ Days since index ED visit } \\
\hline & 7 & 14 & 30 & 90 & 365 \\
\hline Subsequent ED visits, $\mathrm{n}$ & 673 & 825 & 1053 & 1757 & 4146 \\
\hline Follow-up visits, $\mathrm{n}$ & 5749 & 10,552 & 20,032 & 49,639 & 172,597 \\
\hline \multicolumn{6}{|l|}{ Sex } \\
\hline Female & $2760(48.0)$ & $5056(47.9)$ & $9522(47.5)$ & $23,741(47.8)$ & $84,181(48.8)$ \\
\hline Male & $2989(52.0)$ & $5496(52.1)$ & $10,510(52.5)$ & $25,898(52.2)$ & $88,416(51.2)$ \\
\hline \multicolumn{6}{|l|}{ Subsidy group (55 to 64 years of age) } \\
\hline Aboriginal & $120(8.5)$ & $205(7.8)$ & $398(7.9)$ & $1212(9.5)$ & $5100(10.9)$ \\
\hline Government-sponsored program & $335(23.6)$ & $625(23.7)$ & $1155(23.0)$ & $2751(21.6)$ & $9949(21.3)$ \\
\hline Welfare & $294(20.7)$ & $526(20.0)$ & $1009(20.1)$ & $2845(22.3)$ & $10,577(22.6)$ \\
\hline Registrant without subsidy & $670(47.2)$ & $1280(48.6)$ & 2452 (48.9) & $5923(46.5)$ & $21,190(45.3)$ \\
\hline \multicolumn{6}{|l|}{ Diagnosis } \\
\hline Chronic obstructive pulmonary disease & $1187(20.6)$ & $1966(18.6)$ & $3330(16.6)$ & $7084(14.3)$ & $20,897(12.1)$ \\
\hline \multicolumn{6}{|l|}{ Physician type } \\
\hline General practitioner & $3941(68.6)$ & $6883(65.2)$ & $12,426(62.0)$ & $30,253(60.9)$ & $107,405(62.2)$ \\
\hline Internal medicine & $468(8.1)$ & $976(9.2)$ & $1949(9.7)$ & $4709(9.5)$ & $13,907(8.1)$ \\
\hline Respiratory medicine & $143(2.5)$ & $295(2.8)$ & $686(3.4)$ & $1840(3.7)$ & $5287(3.1)$ \\
\hline \multicolumn{6}{|l|}{ Facility type } \\
\hline Practitioner's office & $2549(44.3)$ & 4981 (47.2) & $9734(48.6)$ & $24,833(50.0)$ & $86,375(50.0)$ \\
\hline Active treatment hospital & 2763 (48.1) & $4718(44.7)$ & $8524(42.6)$ & $20,096(40.5)$ & $67,319(39.0)$ \\
\hline
\end{tabular}

Data presented as $n$ (\%) unless otherwise indicated 
TABLE 4

Time (days) to nonemergency department follow-up visits for the discharged cohort $(n=7302)$

\begin{tabular}{llc}
\hline & Median (95\% Cl) & P \\
\hline Sex & & 0.063 \\
Female & $13(12-13)$ & \\
Male & $13(13-15)$ & \\
Age group, years & & $<0.001$ \\
$55-59$ & $19(17-22)$ & \\
$60-64$ & $17(14-19)$ & \\
$65-69$ & $13(12-15)$ \\
$70-74$ & $12(10-13)$ & \\
$75-79$ & $10(9-12)$ & \\
$\geq 80$ & $10(9-12)$ & \\
Subsidy group (55 to 64 years of age) & & \\
Aboriginal & $16(13-22)$ \\
Government-sponsored program & $15(13-19)$ & \\
Welfare & $10(8-13)$ & \\
Registrant without subsidy & $22(20-27)$ \\
Region(s) of residence (Alberta) & $10(8-11)$ \\
Calgary & $10(9-11)$ \\
Edmonton & $16(15-17)$ & \\
Nonmajor urban & & \\
\hline
\end{tabular}

presenting to Alberta EDs with an exacerbation were hospitalized, compared with 32\% in ED patients with COPD. Moreover, the frequency of critical care admissions and death were higher than for the asthma cohort. One of the reasons for the differences and variability in admissions identified in the present study may be due to a lack of a clear definition for clinicians on who requires admission. In a study of admission after ED care (2), North American investigators found that six patient factors were independently associated with hospital admission. In a more selective sample, Canadian investigators recently demonstrated (14) that historical-, severity- and treatment-related factors were strongly associated with hospital admission. Validation of these results is required; however, the data here and elsewhere suggest that clinical tools to assist physicians in making these admission decisions may be important for patient safety.

Patients with COPD often require prolonged LOS, and those who are admitted must endure the delays associated with ED overcrowding, especially in urban, high-volume EDs (15). These times seem to correspond with other COPD ED research $(11,12)$, but are longer than treatment periods for patients with asthma (13). Given that many of these patients have serious comorbidities (eg, coronary artery disease, heart failure, diabetes and hypertension), advanced age and respond less completely to treatments further exacerbates ED crowding even when patients are discharged from the ED. Finally, knowing that many patients with acute COPD require respiratory support in the form of noninvasive ventilation or intubation, these results suggest that the economic consequences of this disease are significant. Clearly, efforts to reduce ED visits and severity of disease at presentation for patients with COPD should be a priority within this and other health care settings.

Canadian COPD consensus guidelines recommend that patients be regularly followed for their condition by a primary care provider or, in cases of severe disease, a specialist (ie, pulmonologist) (1). Following an acute exacerbation requiring ED presentation, this follow-up reassessment is even more critical. While largely unstudied, the guidelines recommend a reassessment by the primary care provider four to six weeks following a hospitalization;

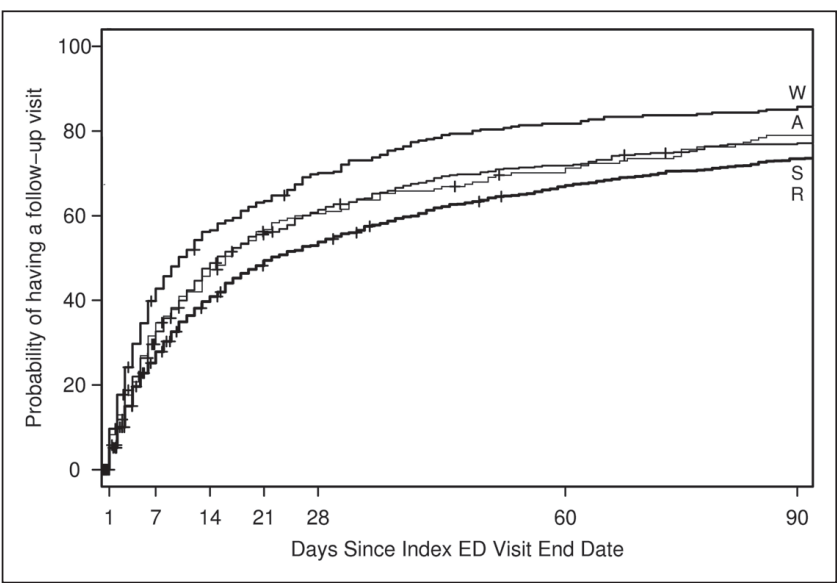

Figure 2) Time to first follow-up visit after discharge from the emergency department (ED). Discharged cohort with age younger than 65 years according to subsidy group. A Aboriginal; R Registrant without subsidy; S Government-sponsored programs; W Welfare

however, the timing of this follow-up is unclear after an ED visit (3). ED visits often represent failure of the chronic management of patients with COPD; therefore, it makes good sense that follow-up with the primary care provider should be encouraged and completed in a timely manner. Despite this, the frequency and intensity of post-ED follow-up visits are not known in great detail because most COPD follow-up reported in research studies is spuriously high due to study participation.

For a large proportion of patients discharged from the ED during a one-year period, follow-up visits were made in nonED settings for a variety of reasons and at different intervals. Approximately 21\% of follow-up visits in the seven days after ED visits were COPD related. Only approximately $31 \%$ of the individuals had any follow-up visit during the first seven days after ED discharge. Finally, this follow-up was influenced by other factors. For example, a higher proportion of the $\mathrm{W}$ subgroup had a follow-up visit within seven days (43\%) compared with the other subgroups (28\% to $35 \%$ ). This finding may not have been predicted in this population; however, our methodology did not provide sufficient data to explore this further. Clearly, follow-up after an important ED visit for COPD is not occurring evenly and successfully across all groups in Alberta, and requires more in-depth study.

Relapse is an important issue after ED discharge. Early relapse may signify a failure of appropriate ED decision making (eg, treatment and/or disposition), while later relapses may be related to medical, environmental or severity issues. In a study of relapse after discharge (16), North American investigators found that patients with COPD suffered considerably after the ED discharge. In a more selective sample, Canadian investigators recently demonstrated (17) that past COPD control (ED visits in the past two years), ED treatments (oxygen) and initial vital signs (respiratory rate, earliest peak flow and oxygen saturation), but not treatment issues, were associated with COPD relapse. Validation of these results should be completed before widespread acceptance in Canada; however, it is clear that efforts to reduce relapse and improve quality of life after discharge should be continued.

The present study has several limitations. The study was based on administrative databases that contained limited clinical information, which was not designed for specific research questions. The databases used in the present study are unable to capture all cases of acute COPD visits to the health care system. Many individuals may report to non-ED settings for COPD exacerbations; 
however, we suspect this is less so than for younger patients with respiratory conditions such as asthma. Individuals presenting to EDs for COPD may not be representative of all individuals with COPD. Given the data available at the administrative level, we were unable to determine the influence of either the pre-ED treatment or contact with the health care system. In particular, we did not know what medications were used before the ED visit. In addition, A status in the present study only denoted those with 'Treaty' status through registration with Health Canada, thus, nontreaty status (those who do not belong to a First Nation that has signed a treaty with the federal government) and Métis (people of mixed First Nation and European ancestry) were not included. Finally, the clinical treatment received in EDs across Alberta is likely to vary considerably, which could impact these findings.

Despite these limitations, the ACCS data have been shown to be valid and reliable, and any biases in our findings are likely limited. Moreover, the ACCS contains comprehensive information and, when linked to demographic and outcomes data, provides an important advantage over simple cross-sectional research.

Overall, the current study demonstrated that ED visits for acute COPD are common, and more frequently result in admission and death than other acute respiratory emergencies such as asthma (10). Compared with another major chronic disease seen in this age group, heart failure patients presented to the ED more frequently than COPD patients; however, discharged patients had an even higher rate of repeat visits than admitted patients (18). Patients discharged from the ED experience delayed

\section{REFERENCES}

1. O'Donnell DE, Aaron S, Bourbeau J, et al. Canadian Thoracic Society recommendations for management of chronic obstructive pulmonary disease - 2007 update. Can Respir J 2007;14(Suppl B):5B-32B.

2. Tsai CL, Clark S, Cydulka RK, et al. Factors associated with hospital admission among emergency department patients with chronic obstructive pulmonary disease exacerbation. Acad Emerg Med 2007;14:6-14.

3. Global Initiative for Chronic Obstructive Lung Disease. Global strategy for diagnosis, management and prevention of COPD. <http://www.goldcopd.com/> (November 14, 2010).

4. Rowe BH, Cydulka R, Tsai CL, et al. Comparison of Canadian versus United States emergency department visits for chronic obstructive pulmonary disease exacerbation. Can Respir J 2008; 15:295-301.

5. Alberta Health and Wellness. Ambulatory Care in Alberta Using Ambulatory Care Classification System Data. <http://www.health. gov.ab.ca/resources/publications/ACCSreportAug04.pdf p.> Edmonton, 2004. (Accessed on October 29, 2010).

6. Practice Management Information Corporation. International Classification of Diseases, 9th Revision, 3rd edn. Clinical Modification. Los Angeles, 1989.

7. Canadian Institute for Health Information. The Canadian Enhancement of ICD-10. Ottawa, 2001.

8. Colman I, Dryden DM, Thompson AH, et al. Utilization of the emergency department after self-inflicted injury. Acad Emerg Med 2004:11:136-42.

9. Voaklander DC, Kelly KD, Sukrani N, et al. Sledding injuries presenting to the emergency department in a northern city. Acad Emerg Med 2001;8:629-35. follow-up and often require repeat ED visits. Interventions to improve reassessment designed to reduce COPD-related relapses should be explored.

ACKNOWLEDGEMENTS: This study was based, in part, on data provided by Alberta Health and Wellness. The interpretation and conclusions contained herein are those of the researchers and do not necessarily represent the views of the Government of Alberta. Neither the Government nor Alberta Health and Wellness express any opinion in relation to this study. The authors greatly appreciate the efforts of Yan Jin at Alberta Health and Wellness in facilitating access to the data and Dan Metes, MSc, for assisting in data analysis. The authors appreciate the cooperation of The COPD and Asthma Network of Alberta (CANA, www.canahome.org), especially Ms Eileen Gresl (CANA Manager), in facilitating involvement of these decision makers.

FUNDING: This work was made possible by an operating grant from the Canadian Institutes of Health Research and funding from The Lung Association, Alberta \& Northwest Territories. Dr Rowe is supported by the Government of Canada as a 21st Century Canada Research Chair. Dr Rosychuk is supported by the Alberta Heritage Foundation for Medical Research as a Health Scholar. Dr Rowe has received research funding and speaking fees from AstraZeneca Canada, GlaxoSmithKline Canada and Abbott Canada.

10. Kelly KD, Rowe BH, Lissel H, et al. Sports and recreation head injury treated in the emergency department. Clin J Sport Med 2001;11:77-81.

11. Cydulka RK, Rowe BH, Clark S, et al. Management of asthma and COPD exacerbations among patients age $55+$ presenting to the emergency department: The Multicenter Airway Research Collaboration. J Am Geriatr Soc 2003;51:908-16.

12. Indian and Northern Affairs Canada. Terminology. $<$ http://www.ainc-inac.gc.ca/ap/tln-eng.asp > (Accessed on November 15, 2010).

13. Rowe BH, Voaklander DC, Wang D, et al. Asthma presentations by adults to emergency departments in Alberta, Canada: A large population-based study. Chest 2009;135:57-65.

14. Rowe BH, Villa-Roel C, Abu-Laban R. Admissions to Canadian hospitals for acute COPD: A prospective multicentre study. Acad Emerg Med (In press).

15. Rowe BH, Bond K, Ospina M, et al. Frequency, determinants, and impact of overcrowding in emergency departments in Canada: A national survey of emergency department directors. Ottawa: Canadian Agency for Drugs and Technologies in Health, 2006.

16. Kim S, Emerman CL, Cydulka RK, et al. Prospective multicenter study of relapse following emergency department treatment of COPD exacerbation. Chest 2004;125:473.

17. Rowe BH, Willis V, Mackey D, et al. Prospective multicenter study of treatment and relapse following emergency department discharge for acute COPD. CJEM 2007;9:204.

18. Ezekowitz JA, Bakal JA, Kaul P, et al. Acute heart failure in the emergency department: Short and long-term outcomes of elderly patients with heart failure. Eur J Heart Fail 2008;10:308-14. 


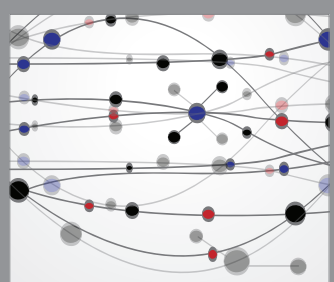

The Scientific World Journal
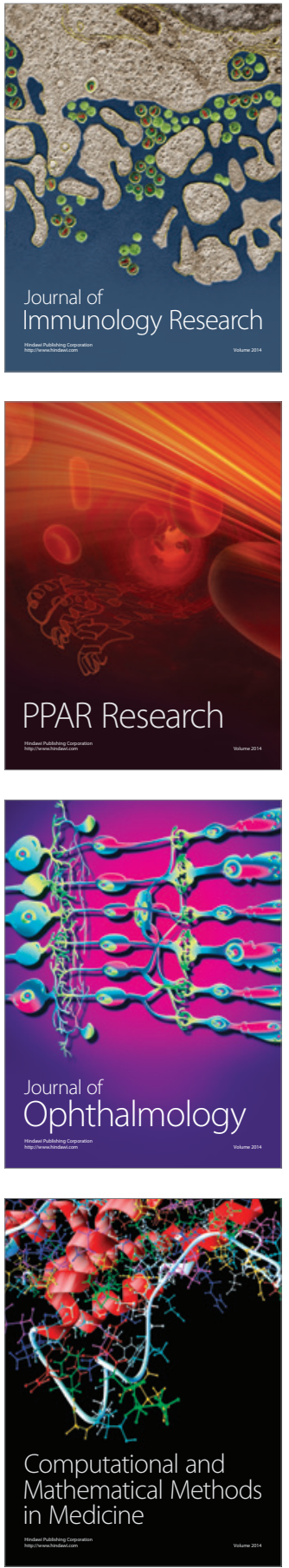

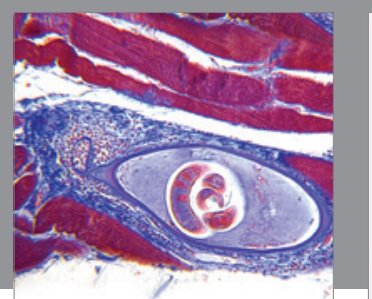

Gastroenterology Research and Practice

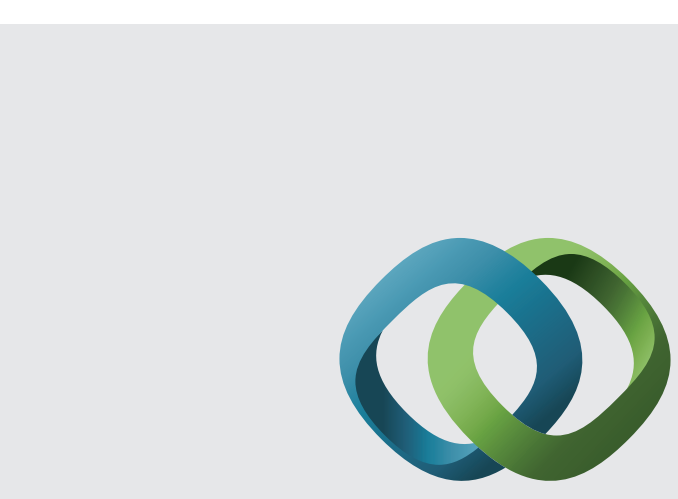

\section{Hindawi}

Submit your manuscripts at

http://www.hindawi.com
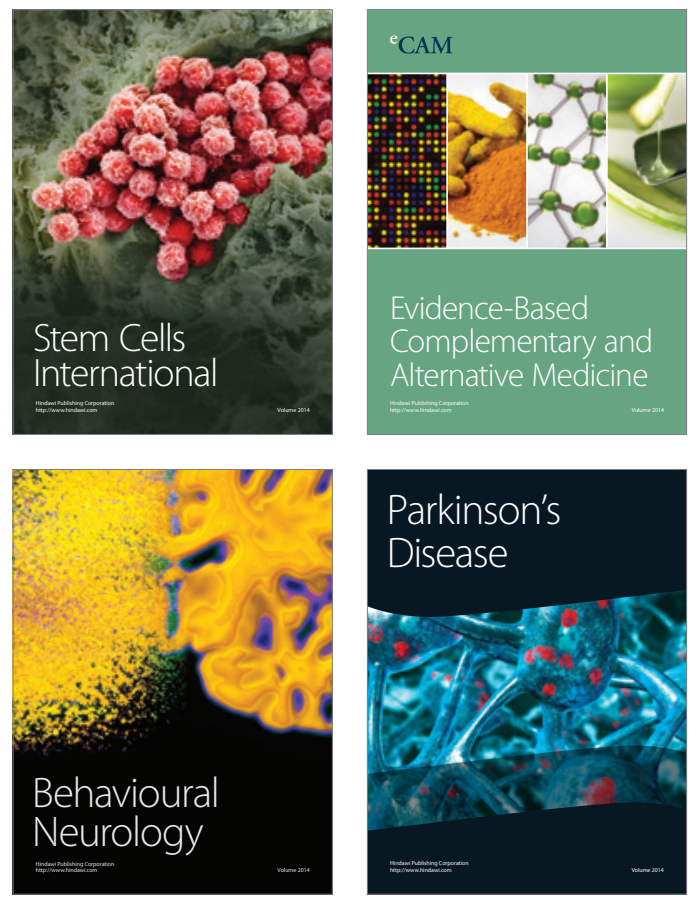
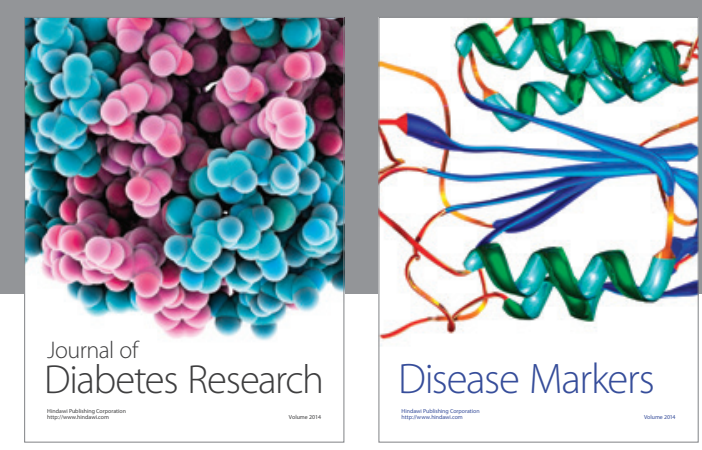

Disease Markers
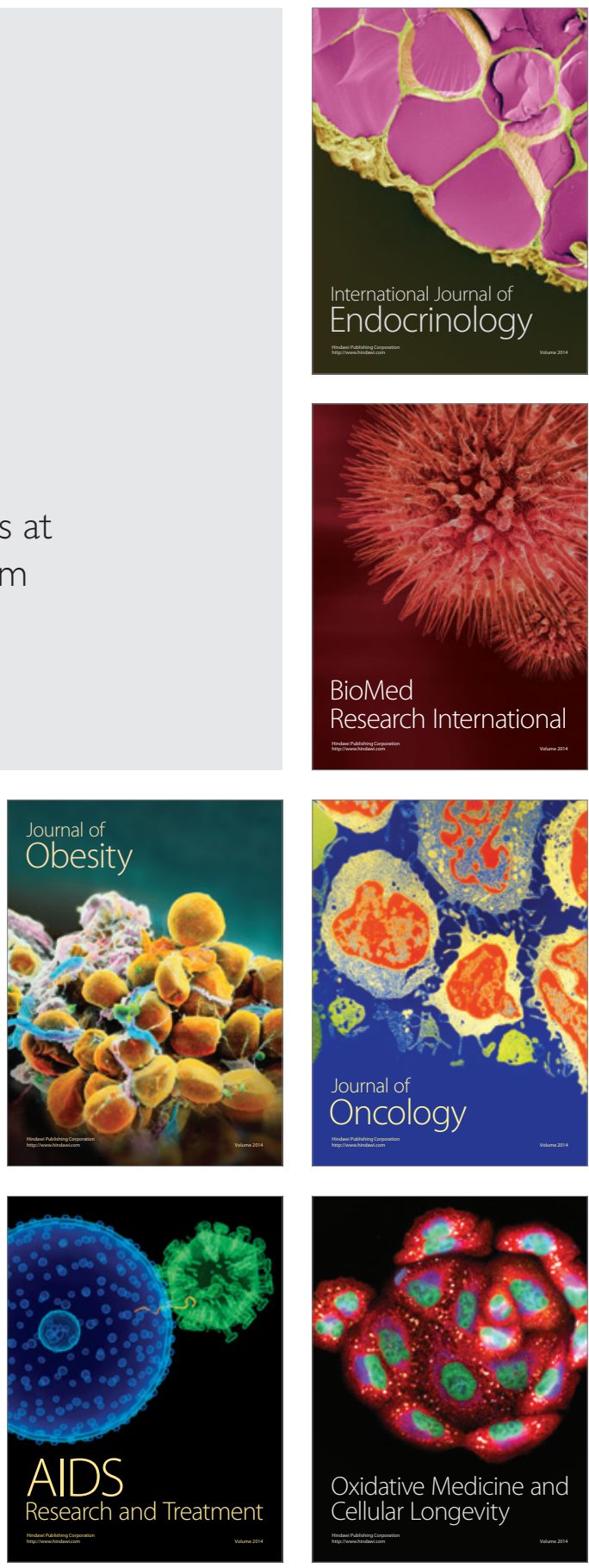